\title{
thebmi
}

Letters Asylum seekers' health needs

\section{Pregnant asylum seekers}

BMJ 2010; 341 doi: http://dx.doi.org/10.1136/bmj.c4691 (Published 27 August 2010) Cite this as: BMJ 2010;341:c4691

\author{
Helen E D Burchett, research fellow1, Ros Bragg, director2 \\ ${ }^{1}$ London School of Hygiene and Tropical Medicine, London WC1E 7HT \\ ${ }^{2}$ Maternity Action, London EC1Y $8 R T$
}

helen.burchett@lshtm.ac.uk

McCartney mentioned Aspinall and Watters' report, which highlights poorer pregnancy outcomes among refugees.1 2 Let there be no doubt about what poorer means: asylum seekers and refugees are more likely than the general population to die during pregnancy or childbirth.3 Maternal health complications and neonatal deaths and complications are likely to be even more prevalent.

In 2003 the House of Commons Select Committee on Health gathered evidence on the poor access to health services for pregnant asylum seekers.4 It noted that pregnant women were being detained in immigration centres, despite the government's policy that pregnant women should not usually be considered suitable for detention.

Some of the evidence came from qualitative research undertaken by the Maternity Alliance.5 It found that the biggest challenge was knowing what kinds of services and support were available.

Pregnant women tend to be among the most vulnerable and so act as a key indicator for service provision-if their risk of poor health is increased, services for others are also likely to be seriously problematic.

Maternity Action (www.maternityaction.org.uk), a charity campaigning to end inequality and promote the health and wellbeing of all pregnant women and their partners and children, is developing training courses for midwives, with funding from Comic Relief, to improve care for women refugees and asylum seekers. However, without broader policy interventions (and their enforcement), the health and healthcare experiences of these groups are likely to remain poor.

\section{Notes}

Cite this as: BMJ 2010;341:c4691

\section{Footnotes}

- Competing interests: None declared. 


\section{References}

1. McCartney M. Poor diagnosis for asylum seekers' health needs. BMJ2010;341:c4106. (17 August.)

2. Aspinall P, Watters C. Refugees and asylum seekers: A review from an equality and human rights perspective. Equality and Human Rights Commission, 2010.

3. Confidential Enquiry into Maternal and Child Health (CEMACH). Saving mothers' lives: reviewing maternal deaths to make motherhood safer-2003-2005. The seventh report of the Confidential Enquiries into Maternal Deaths in the United Kingdom. London: CEMACH, 2007.

4. House of Commons Select Committee on Health. Inequalities in access to maternity services: eighth report of session 2002-03. London: Stationery Office, 2003.

5. McLeish J. Mothers in exile: maternity experiences of asylum seekers in England. London: Maternity Alliance, 2002. 